\title{
How much do the Patients with Acute Myocardial Infarction Know about Chest Pain, Thrombolytic Therapy, and Other Factors Affecting the Treatment Time in the Emergency Room?
}

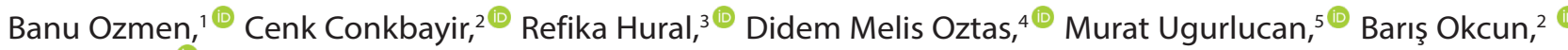 \\ Zerrin Yiğit' ${ }^{2}$
}

Istanbul University-Cerrahpasa, ${ }^{1}$ Istanbul - Turkey

Near East University, ${ }^{2}$ Nicosia - Cyprus

Doctor Burhan Nalbantoglu State Hospital ${ }^{3}$ Lefkosa - Cyprus

Bagcilar Training and Research Hospital, ${ }^{4}$ Istanbul - Turkey

Istanbul Medipol University, ${ }^{5}$ Istanbul - Turkey

\section{Abstract}

Background: Treatment time in the emergency room for acute myocardial infarction is very important and can be life-saving if one understands the importance of a patient's chest pain.

Objetice: The aim of this study is to evaluate how much patients entering the emergency room due to acute myocardial infection (AMI) know about chest pain and thrombolytic therapy .

Materials and Methods: One hundred fifty patients (126 males,14 females) from three different institutes with complaints of chest pain were randomly chosen to participate in this study. The mean age of the patients was 55.4 \pm 11.2 years $(71+33)$. Patients were asked to fill out a questionnaire consisting of 70 questions within the first seven days. All differences in categorical variables were computed using the $\chi 2$-test and Fisher Exact test. A two-tailed hypothesis was used in all statistical evaluations, and $p<0.05$ was considered significant.

Results: It was observed that $17 \%$ of the patients came to the hospital within the first 30 minutes; $18.3 \%$ of them came to the hospital between 30 minutes and 1 hour; $27.5 \%$ of them came to the hospital between 1 hour and 3 hours; and $21.4 \%$ of them came to the hospital more than 6 hours after symptoms began. It was also observed that $68 \%$ of the patients were not aware of the AMI, and $96 \%$ of them had no prior knowledge of antithrombolytic therapy.

Conclusion: Because the majority of the patients did not have enough information about AMI, a training program should be implemented to ensure that people to come to the hospital earlier.

Keywords: Coronary Artery Disease; Myocardial Infarction; Chest Pain; Emergency Medical Services; Thrombolytic Therapy.

\section{Introduction}

Coronary artery disease is the leading cause of death for men and women in Turkey and worldwide. In our country, acute coronary syndrome and acute myocardial infarction (AMI) cause approximately $32 \%$ of all yearly mortality.${ }^{1}$ Coronary Artery Disease can manifest itself in the form of cardiac arrest, angina pectoris, or AMI. ${ }^{2}$
Recent research has shown that $25-50 \%$ of the patients with AMI come to the hospital more than six hours after symptoms begin. ${ }^{3}$ Some reasons that patients may delay coming to the hospital are a lower level of education and awareness, concern about causing other people to panic, not recognizing the symptoms, not accepting the disease, an attempt to avoid hospital costs, fear of the hospital, or

Mailing Address: Cenk Conkbayir, MD

Near East University Cardiology Department

Nicosia, Cyprus

e-mail: cenkconk@hotmail.com 
the patient's own self-treatment. ${ }^{4,5}$ If it is recognized that the symptoms are related to AMI, the time it takes to be admitted to the hospital is diminished .6,7

Thrombolytic therapy for AMI is one of the most important developments in cardiology. When thrombolytic therapy is used as early as possible, the efficiency of the therapy is maximized, the infarct area is reduced, and the left ventricular function will be optimally protected. ${ }^{8}$ The thrombolytic therapy administered in response to AMI results in a $25-50 \%$ decrease in mortality when administered in conjunction with conventional therapy. ${ }^{9-15}$ Weaver et al., ${ }^{16}$ have reported that the time to arrival at the hospital for patients in developed countries is four hours. Nevertheless, the public should be aware of the importance of coming to the hospital as soon as possible after the appearance of symptoms. However, these days, this can be achieved for $1 / 3$ patients with a recommendation for thrombolytic therapy, even in developed countries with good health organizations. Public health efforts are needed to increase the recognition of the major heart attack symptoms in both the general public and groups at high risk for an acute cardiac event, especially in socioeconomically disadvantaged subgroups, including people with low levels of education, low household incomes, and no health insurance coverage. ${ }^{17}$

The objective of this study is to investigate how much the patients coming to the hospital with a diagnosis of AMI know about Coronary Artery Disease, Coronary Artery Disease therapy, AMI, thrombolytic therapy, and the importance of coming to the hospital upon recognizing the first sign of symptoms.

\section{Materials and Methods}

One hundred and fifty patients, including 70 patients from the İstanbul University Cardiology Institute, 42 patients from Istanbul University Cerrahpasa Medical Faculty, and 38 patients from Şişli Etfal Hospital, were randomly chosen to be included in this study. Randomization is performed by the free web based system at: http://www.tufts.edu/ gdallal/PLAN.HTM. All patients complained of chest pain and were diagnosed with AMI. The mean age of the patients was $55.4 \pm 11.2$ years. This study used a convenience sampling size, and patients were chosen at random.

Patients were interviewed within the first seven days of hospitalization and asked to fill out a questionnaire consisting of 70 questions. The questions contained within the questionnaire were chosen to evaluate the patients' level of education, the symptoms that led the patients to come to the hospital, the time of onset of these symptoms, the patients' reactions to the symptoms, and the time that the patients took to arrive at the hospital. The patients who reported having no complaints within 48 hours after filling out the questionnaire were considered to be patients with no symptoms. The location of the AMI, presentation, and clinical outcomes of the patients were also evaluated.

\section{Statistical Analysis}

Statistical analysis was performed using SPSS (SPSS for Windows, SPSS Inc, Chicago, IL) 15.0 program package. The Shapiro-Wilk test was used for the analysis of compliance with the normal distribution. Continuous variables are presented as mean \pm standard deviation. Categorical variables are presented as frequencies and percentage. All differences in categorical variables were computed with the ${ }^{2}$ test and Fisher Exact test. A twotailed hypothesis was used in all statistical evaluations, and $\mathrm{p}<0.05$ was considered significant.

\section{Results}

Seventy-five of the patients (49.9\%) included in this study presented prior AMI; 43 of the patients $(28.7 \%)$ reported inferior $\mathrm{AMI} ; 13$ of the patients $(8.7 \%)$ had non-Q wave MI; and 19 of the patients (12.7\%) presented AMI in other regions. Nineteen of this study's patients $(12.6 \%)$ had experienced at least two AMIs, 17 of whom $(89.5 \%)$ were male.

One hundred and forty-four of the patients complained of chest pain (retrosternal, spreading to the chest or to the precordial region, not responsive to nitrate, and continuing for more than 30 minutes); two of the patients complained of pain in the arms; three of the patients complained of abdominal pain; and one of the patients came to the hospital with other complaints. Fifty-six percent of the patients described their pain as a pressing type; $28 \%$ of the patients described their pain as a stinging type; and $16 \%$ of the patients described their pain as a burning type (Table-1).

Ninety-three percent of the patients had experienced prior chest pain. No significant differences were observed between the patients who reported prior chest pain and those who did not in terms of gender, education, and income level. 
Table 1 - The Features of Chest Pain in Patients

\section{Type of Chest Pain}

\begin{tabular}{|c|c|c|c|}
\hline \multirow{10}{*}{ Localization of Chest Pain: } & Pressing type & & $84(56 \%)$ \\
\hline & Burning Type & & $24(16 \%)$ \\
\hline & Drilling Type & & $42(28 \%)$ \\
\hline & Retrosternal & & $84(56 \%)$ \\
\hline & Precordial & & $24(16 \%)$ \\
\hline & Diffuse & & $36(24 \%)$ \\
\hline & Other & & $6(4 \%)$ \\
\hline & & Pain in arms & 2 \\
\hline & & Abdominal Pain & 3 \\
\hline & & Other & 1 \\
\hline \multirow{5}{*}{ Place where the symptoms begun: } & Office (Job) & & $14(9.3 \%)$ \\
\hline & Home & & $114(76 \%)$ \\
\hline & Medical Institution & & $3(2 \%)$ \\
\hline & Car & & $1(0.7 \%)$ \\
\hline & Other & & $18(12 \%)$ \\
\hline \multirow{2}{*}{ Activity while symptoms were occurring: } & Effort & & $96(64 \%)$ \\
\hline & Rest & & $54(36 \%)$ \\
\hline
\end{tabular}

A majority of patients, $76.7 \%$, had no information about chest pain and its causes, while $22 \%$ of the patients received information from their physicians and $1.3 \%$ of the patients received information from other people. The percentage of patients who were aware of the relationship between chest pain and the heart was $51.3 \%$ (mean age $=57.3 \pm 9.2$ years), while the percentage of patients who were unaware of this relationship was $48.7 \%$ (mean age $=53.3 \pm 3.6$ years). A significant difference in age was observed between the two groups ( $p=0.021)$. No significant difference was found in terms of gender, level of education, and economic situation. Nevertheless, the first degree relatives of the patients who were aware of the relationship between chest pain and the heart had more ischemic heart disease. It was determined that $68 \%$ of the patients had no information about AMI. The level of education and economic situation of the patients who had information about heart attacks was significantly higher than those patients who had no information about heart attacks ( $p=0.001$ vs. $p<0.01$, respectively). Of the patients who had information about heart attacks, $41.6 \%$ received the information from other people, while $29.12 \%$ received the information from their physician (Table-2). Of the patients who had had AMI twice, $84.2 \%$ claimed that they were informed in the hospital or by the physician, and $15.8 \%$ claimed that they were not informed again.

When evaluating the initial behavior of the patients at the onset of chest pain, $70.9 \%$ of the patients who had not had chest pain before preferred to rest, while only $34.4 \%$ of the patients who had had chest pain before preferred to rest $(p<0.01)$. It should be noted that the patients who had not had chest pain before were not taking aspirin, while $6.45 \%$ of the patients who had chest pain before were taking aspirin $(\mathrm{p}=0.05)$. Of the patients who had not had chest pain before, $1.81 \%$ first took Isordil $5 \mathrm{mg}$ SL, whereas $21.5 \%$ of the patients who had had chest pain before first took Isordil $5 \mathrm{mg}$ SL $(p<0.001)$ (Table-3).

It was found that $58.1 \%$ of the patients who had chest pain after taking precautions came to the hospital, while only $9 \%$ of the patients who had no chest pain after taking precautions came to the hospital $(p<0.0001)$. Twenty percent of those who had had chest pain before came to the hospital if the chest pain did not subside after 
Table 2 - The knowledge level of the patients and their sources of information

\begin{tabular}{lc}
\hline No information & $102(68 \%)$ \\
\hline Media & $9(18.75 \%)$ \\
\hline Books & $2(4.16 \%)$ \\
\hline Physicians & $14(29.16 \%)$ \\
\hline Other people & $20(41.66 \%)$ \\
\hline Media + Other people & $3(6.25 \%)$ \\
\hline
\end{tabular}

Table 3 - The initial behaviors exhibited by the patients at the onset of chest pain

\begin{tabular}{|c|c|c|c|}
\hline Type of Chest Pain & $\begin{array}{l}\text { No Chest Pain } \\
\text { Experienced before } \\
(n=55)\end{array}$ & $\begin{array}{c}\text { Chest Pain } \\
\text { Experienced before } \\
(\mathrm{n}=95)\end{array}$ & p-value \\
\hline Rest & $39(70.90 \%)$ & $32(34.40 \%)$ & $<0.01 \dagger$ \\
\hline Come to hospital & $10(18.80 \%)$ & $12(12.90 \%)$ & $0.6+$ \\
\hline Taking aspirin & 0 & $6(6.45 \%)$ & N/A \\
\hline Taking Isordil SL (5 mg) & $1(1.81 \%)$ & $20(21.50 \%)$ & $<0.001 \dagger$ \\
\hline Taking antihypertensives & 0 & $3(3.22 \%)$ & $\mathrm{N} / \mathrm{A}$ \\
\hline $\begin{array}{l}\text { Taking analgesics/anti- } \\
\text { inflammatory drugs }\end{array}$ & $4(7.27 \%)$ & $8(8.60 \%)$ & $0.4^{*}$ \\
\hline Call his/her MD & $1(1.81 \%)$ & $8(8.60 \%)$ & $0.7+$ \\
\hline Return home & $2(3.63 \%)$ & $4(4.30 \%)$ & $0.8+$ \\
\hline
\end{tabular}

taking Isordil $5 \mathrm{mg}$ SL, while $3.6 \%$ of those who had not experienced chest pain before came to the hospital if the chest pain did not subside after taking Isordil $5 \mathrm{mg}$ SL $(p=0.006)$. There was no significant difference in gender, job, level of education, and economic situation between those patients who used SL nitrate and those that did not. The mean age of those who used nitrate was higher (Table-4).

It was determined that $17 \%$ of the patients who were experiencing a first time AMI came to the hospital within the first 30 minutes after the onset of symptoms; $18.3 \%$ of them came between 30 minutes and 1 hour after the onset of symptoms; $27.5 \%$ of them came between 1 hour and 3 hours after the onset of symptoms; 15.3\% of them came between 3 hours and 6 hours after the onset of symptoms; and $21.4 \%$ of them came more than 6 hours after the onset of symptoms. For the patients experiencing AMI for the second time, 21\% came to the hospital in the first 30 minutes, $15.8 \%$ came to the hospital between 30 minutes and 1 hour after the onset of symptoms; $26.3 \%$ came to the hospital between 1 hour and 3 hours after the onset of symptoms; $15.8 \%$ came to the hospital between 3 hours and 6 hours after the onset of symptoms; and 11\% came to the hospital more than 6 hours after the onset of symptoms (Table-5) (Graph 1). No significant differences were observed in the time it took to arrive at the hospital in terms of age, gender, level of education, hospital admittance, and whether the patient had experienced chest pain previously. The length of time it took to arrive at the hospital from home was determined to be 30 minutes. Most of the patients (86\%) did not come to the hospital by ambulance. The percentage of patients who arrived at the hospital by ambulance was $5.3 \%$. 


\begin{tabular}{|c|c|c|c|}
\hline Type of Chest Pain & $\begin{array}{l}\text { No Chest Pain } \\
\text { Experienced before } \\
(n=55)\end{array}$ & $\begin{array}{l}\text { Chest Pain } \\
\text { Experienced before } \\
(n=95)\end{array}$ & p-value \\
\hline Come to the hospital & $54(58.10 \%)$ & $54(58.10 \%)$ & $<0.0001^{*}$ \\
\hline Come to the hospital if the pain does not disappear & $2(3.60 \%)$ & $19(20.00 \%)$ & $0.006+$ \\
\hline Informed about thrombolytic therapy & 0 & $6(6.45 \%)$ & N/A \\
\hline
\end{tabular}

Table 5 - The amount of time it took patients to arrive at the hospital after the start of chest pain

\begin{tabular}{lcc}
\hline & First AMI (n=131) & Second AMI (n=19) \\
\hline First 30 minutes & $23(17.6 \%)$ & $4(21.0 \%)$ \\
\hline 30 min- 1 hour & $24(18.3 \%)$ & $3(15.8 \%)$ \\
\hline $1-3$ hours & $36(27.5 \%)$ & $5(26.3 \%)$ \\
\hline $3-6$ hours & $20(15.3 \%)$ & $3(15.8 \%)$ \\
\hline 6-10 hours & $8(6.1 \%)$ & $2(10.5 \%)$ \\
\hline $10-12$ hours & $20(15.3 \%)$ & $2(10.5 \%)$ \\
\hline
\end{tabular}

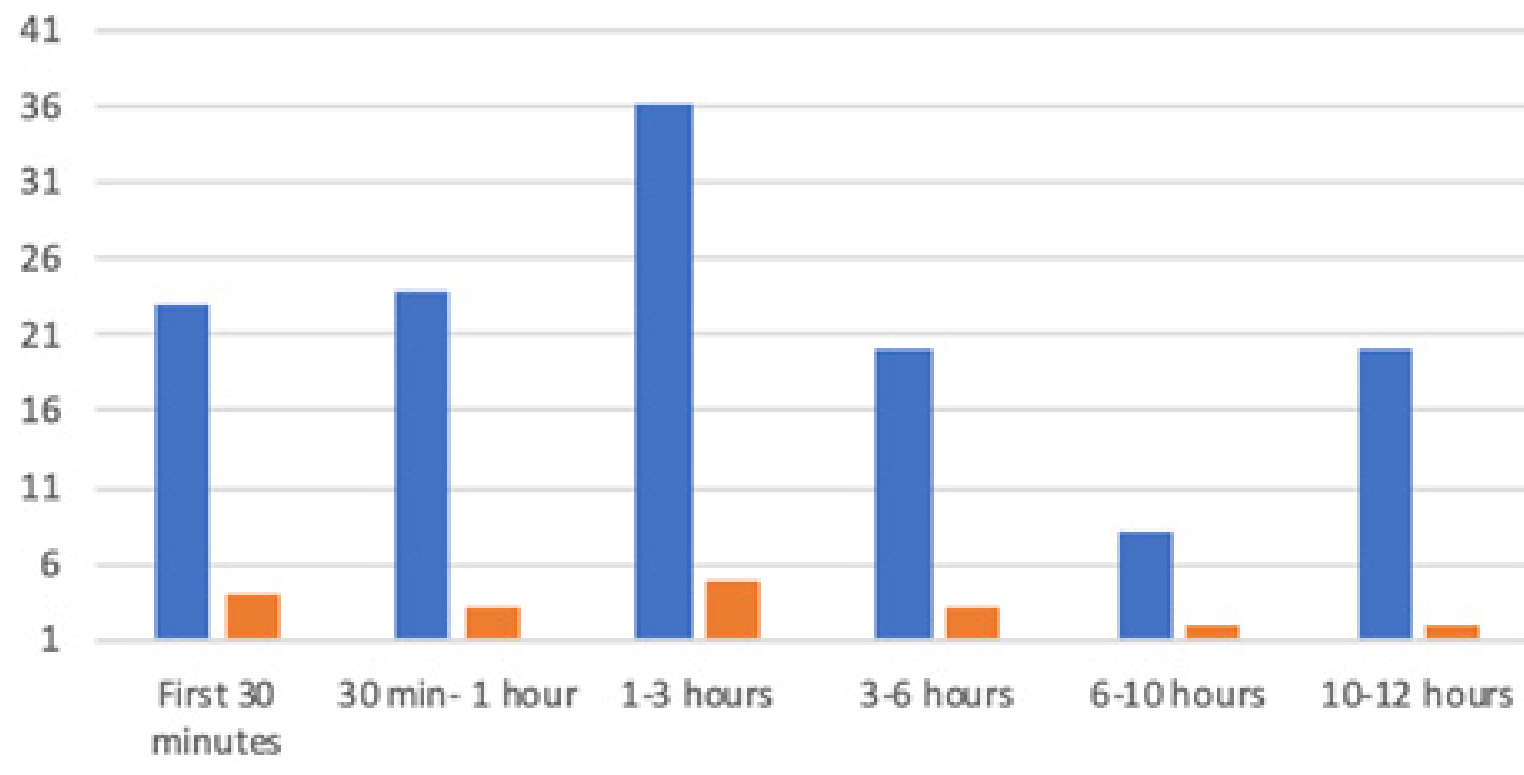

First $\mathrm{AMI}(\mathrm{n}=131) \quad$ Second $\mathrm{AMI}(\mathrm{n}=19)$

Figure 1 - The amount of time it took patients to arrive at the hospital after the start of chest pain 
It was observed that all of the patients thought that it was necessary to come to the hospital if they experienced pain reminiscent of a heart attack. However, 96\% of the patients had no information about antithrombolytic therapy. It was found that antithrombolytic therapy was administered to only 52 of the 150 patients in this study (34.6\%). Of the patients hospitalized due to AMI, 78.7\% were not informed about their status and the therapy that was applied during hospitalization.

\section{Discussion}

Chest pain is a major symptom of AMI. Chest pain is most commonly experienced as retrosternal pain which spreads to the chest wall, neck, and the right and left arms. The pain is usually of a pressing type and may be accompanied by nausea and dyspnea.

In this study, $96 \%$ of the patients had chest pain. The localization of the pain was retrosternal for $58 \%$ of the patients and precordial for $32 \%$ of the patients. Pain was described as a pressing type for $56 \%$ of the patients, a pricking type for $28 \%$ of the patients, and a burning type for $16 \%$ of the patients. In a study by Zerwic et al., the authors reported that the percent of patients experiencing chest pain was $99.8 \%$, that the localization of the chest pain was retrosternal for $97.5 \%$ of patients, and that $93 \%$ of the patients described the pain as a pressing type. ${ }^{18}$

In $76 \%$ of our patients, it was observed that the symptoms began at home. It was also observed that $64 \%$ of the patients were doing exercise when the symptoms began. These results are similar to the findings of Dracup et al., ${ }^{5}$ and Ashton. ${ }^{19}$

In $62 \%$ of the patients, chest pain was reported. It was observed that $51.3 \%$ of the patients were aware of the relationship between the experience of chest pain and the occurrence of Coronary Artery Disease. The mean age of the patients who were aware of this relationship was significantly higher than those who were not aware of this relationship. The increase in ischemic heart disease with age could explain this observation. Additionally, in the REACT study.$^{20}$, the knowledge level of elderly patients was higher than that of middle-aged patients. In our study, no differences were found between the knowledge level, economic situation, jobs, or gender of the patients with ischemic heart disease. In the REACT study, no differences were found between the knowledge level and gender of the patients, whereas a strong correlation was found between the level of education, and the economic situation of the patients. In the present study, it was observed that people who had first degree relatives with ischemic heart disease were well informed about chest pain. This evidence suggests that the patient's experiences in the first and second degree are effective in educating people. Similar results were found in the REACT study. ${ }^{20}$ It was found that more than half of the patients did not know that chest pain may originate from the heart. Those who were aware of the relationship between chest pain and the heart were patients who had previously visited a medical doctor (MD) for the same complaint (22\%). They were informed by the MD directly, while other medical staff did not inform them. This illustrates that the medical staff does not properly educate at-risk patients. Moreover, visual and printed media did not contribute to informing the patient.

The present study found that only $40 \%$ of the patients with complaints of chest pain - including those experiencing AMI for the second time - had visited any health institution. For an efficient therapy, the awareness of the patient as to the symptoms of a heart attack and informing the patient about the importance of coming to the hospital as soon as possible are very important. Our study also determined that the majority of patients prefer to rest initially when the chest pain first begins. Other behaviors preferred by the patients at varying frequencies were as follows: coming to the hospital, sublingual administration of Isordil $5 \mathrm{mg}$, administration of analgesics and/or anti-inflammatory drugs, contacting the patient's physician, returning home if the patient had been away from home, taking aspirin, or taking antihypertensives. Patients who had experienced chest pain before preferred to take Isordil $5 \mathrm{mg}$ SL initially and then take aspirin. Patients who had not experienced chest pain before preferred to rest. Of the patients who came to the hospital first, $58.1 \%$ reported prior chest pain. The percentage of patients who had not experienced prior chest pain and decided to come to the hospital was $9 \%$. A significant difference was found between these two groups.

The present study determined that $20 \%$ of the patients who had chest pain and $36 \%$ of the patients who had no chest pain came to the hospital if the chest pain did not subside with the sublingual administration of Isordil $5 \mathrm{mg}$. Of the patients experiencing AMI for the second time, $57.9 \%$ came to the hospital without taking sublingual Isordil $5 \mathrm{mg}$, while $26.3 \%$ came to the hospital if the chest pain had not subsided after taking one dose of Isordil $5 \mathrm{mg}$. The mean age of the patients who were using Isordil $5 \mathrm{mg}$ was significantly higher than that of the patients who were not using Isordil $5 \mathrm{mg}$. No 
differences were found between the groups in terms of gender, level of education, and economic situation. Because ischemic heart disease is predominantly found in elderly people, they are generally well informed about this disease. The delay in the time it takes patients get to the hospital generally stems from a wrongful evaluation the heart, failure to take the symptoms into account, the cost of visiting the hospital, anxiety experienced by the patients, and attempts of self-treatment by the patients themselves. To improve this situation, efforts should be focused on educating the patients directly. Patients are more informed about heart attacks as compared to what they know about the relationship between chest pain and the heart. It was determined that first degree relatives, other people living around the patients, medical staff, and the media play important roles in informing the patients. People who were well informed about heart attacks were well educated and had higher economic situations.

In many studies, most of the patients stated that chest pain was their major symptom; however, they interpreted this incorrectly, Dracup et al., ${ }^{21,22}$ found that patients evaluated heart attack symptoms and chest pain as being related to GIS pain, muscle pain, fatigue, and respiratory infection. Despite the fact that most patients are aware of the classic symptoms, they do not know how to distinguish the appearance of these symptoms from other ailments, they think that heart attacks should appear with violent pain, and they have a severe lack of awareness. It should be explained to the patients that heart attack symptoms can develop slowly, that symptoms may not be continuous, and that symptoms may vary among individuals. The patient's family should be informed at the same time.

The amount of time between the onset of symptoms and the arrival at the hospital wasn on average, 1-3 hours for both patients who were experiencing AMI for the first time and for patients who were experiencing AMI for the second time. The average time spent in route to the hospital was 30 minutes, and $86 \%$ of the patients came to the hospital in privately owned vehicles. Meischke et al. ${ }^{23}$ found that the average duration of time from the onset of symptoms until the arrival at the hospital was 2 hours, and the percentage of people coming to the hospital by means other than an ambulance was $45 \%$. Mumford et al., ${ }^{4}$ determined that the average time spent before coming to the hospital was 172 minutes (approximately 3 hours). Even though the average time spent before coming to the hospital was similar to that of other studies, patients in our study exhibited a preference for the use of their own private vehicles. This result is because the patients do not realize the significance of their symptoms, and they think that it will be easier and quicker to reach the hospital in their own vehicles. No significant correlation was observed between the time it took to arrive at the hospital and age, level of education, or economic situation. In other studies, the length of time to arrival at the hospital was lower in females when compared to males, in elderly people when compared to younger people, and in people of higher socioeconomic status when compared to people of lower socioeconomic status. Moreover, patients who know the relationship of chest pain with the heart, who are informed about thrombolytic therapy, who have a higher level of education, and who smoke arrived at the hospital more quickly $(5,19,20,24,25)$. Mumford et al., ${ }^{4}$ determined that there was no association between the time it took to arrive at the hospital with age, gender, socioeconomic status, marriage, level of education, being informed about chest pain and ischemic heart disease, family history, where the patient was when symptoms developed, when the symptoms developed, distance to the hospital, where the hospital was located, or the severity of the symptoms. ${ }^{4}$

Thrombolytic therapy is the one of the most important developments that has occurred in the last 20 years in the field of cardiology. As a result of this therapy, not only has the mortality due to AMI encountered in hospitals decreased by $20-25 \%$, but this therapy also prevents impairment of myocardial perfusion and remodeling by ensuring the continuity of blood vessels. ${ }^{6-15}$ In the GISSI study, it was shown that mortality was decreased by $47 \%$ when streptokinase was administered within the first hour following the onset of symptoms, $23 \%$ when administered within 1-3 hours, and 17\% when administered within 3-6 hours. Weaver et al. determined that the average time until arrival at the hospital was 4 hours even in developed countries. ${ }^{16}$ The reasons that reperfusion therapy in AMI patients is not begun earlier was determined to be the patients' failure to realize the significance of the symptoms, the length of time until the patient arrived at the hospital, and the time spent from the evaluation of the patient until the beginning of the reperfusion therapy. ${ }^{16}$

It was observed that $96 \%$ of the patients included in our study had no prior knowledge of thrombolytic therapy. Thrombolytic therapy was administered to $34.6 \%$ of these patients. The patients' understanding of the vital importance of thrombolytic therapy plays an important role in ensuring that patients come to the 
hospital more quickly. Therefore, patients need to be informed about thrombolytic therapy.

As a result, it is important that the patients have information about heart attacks, chest pain, and thrombolytic therapy. Arrival at the hospital as soon as possible after the onset of symptoms is crucial, especially for both anti-ischemic therapy and efficient thrombolytic therapy, which should be administered as quickly as possible. The present study observed that, because the majority of our patients were unfamiliar with thrombolytic therapy, they spent precious time attempting self-treatment. A small subset of patients showed a preference for using an ambulance to arrive at the hospital. Since ambulances are likely to be the quickest way to reach the hospital, patients must be encouraged to use them.

\section{Limitations}

In this study our sample included only 3 hospitals in Turkey, and therefore may not be representative of the entire population that came to hospital with chest pain. On the other hand, this study does include patients that came to hospital with chest pain. Nevertheless, further study on healthy subjects in this population is warranted.

\section{Conclusion}

Arranging training programs to educate patients will be useful. Considering the effects of the media, it may be useful to request that the media contribute to campaigns and to ensure that the media properly informs patients. ${ }^{24}$ Considering the effects of the people in direct contact with the patients, it will be helpful to include the families

\section{References}

1. Onat A(editor). TEKHARF 2017. Istambul:Logos Yayincilik Tic AS;2017. p. 1-272.

2. Zerwic JJ, King KB, Wlasowicz GS. Perceptions of patients with cardiovascular disease about causes of coronary artery disease. Heartland Lung. 1997;26(2):2:92.

3. Longdon PE, Thompson PL. Helping heart attact victims to save their own lives. MJA. 1997;166(5):228-9.

4. Mumford AD, Warr KV, Owen SJ, Froser AG. Delays in seeking treatment for acute chest pain:implications for achieving earlier.Thtombolysis. Postgrand Med III. 1997;75(880):90-5.

5. Dracup K,Mckinley SM, Moser DK. Australian patients delay in response to heart attack symptoms. MJA. 1997;166(5):233-6.

6. Schimdt SB, Borch MA. The prehospital phase of acute myocardial infarction in the era of thrombolysis. Am J Cardiol. 1990;65(22):1411-5. of the patients and the people around them in any implemented training programs. ${ }^{25}$ This will aid patients in making informed decisions and will be more likely for patients to come to the hospital as soon as possible when it is necessary to do so.

\section{Author Contributions}

Conception and design: Ozmen B, Okcun B, Yigit Z. Acquisition of data: Ozmen B, Conkbayir C, Hural R, Okcun B, Yiğit Z. Analysis and interpretation of the data: Ozmen B, Conkbayir C, Hural R, Oztas DM, Ugurlucan M, Okcun B, Yiğit Z. Writing of the manuscript: Ozmen B, Conkbayir C, Hural R, Okcun B, Yiğit Z. Critical revision of the manuscript for intellectual content: Ozmen B, Conkbayir C, Hural R, Oztas DM, Ugurlucan M, Okcun B, Yiğit Z.

\section{Potential Conflict of Interest}

No potential conflict of interest relevant to this article was reported.

\section{Sources of Funding}

There were no external funding sources for this study.

\section{Study Association}

This study is not associated with any thesis or dissertation work.

\section{Ethics Approval and Consent to Participate}

This article does not contain any studies with human participants or animals performed by any of the authors.

7. Zapka J, Estrabrook B, Gilliand J, Leviton L, Meischke H, Melville S, et al. Healt care provider's perspective on patients delay for seeking car efor symtoms of acute myocardial infarction. Health Educ Behav. 1999;26(5):714-33.

8. Ho MT, Eisenberg MS, Litwin PE, Schaeffer SM, Daman SK. Delay between onset of chest pain and seeking medical care. The effect of public education. Ann Emerg Med. 1989;18(7):727-31.

9. Braunwald E. Myocardial reperfusion, limitation of infact size,reduction of left ventricular dysfunction, and improved survival.Should the pradigm be excepted?. Circulation. 1989;79(2):441-4.

10. The ISAM Study Group.A prospective trial of intravenous streptokinase in acute myocardial infaction (ISAM).Mortality,morbidity and infarct size at 21 days. N Engl J Med. 1986;314(23):1465-71. 
11. Wilcox RG, Lippe G, Olsson CG, Jensen G, Skene AM, Hampton JR. Trial of tissue plasminogen activator for mortality reduction in acute myocardial infarction. Anglo-Scandinavian Study of Early Thrombolysis (ASSET). Lancet. 1988;2(8610):525-30.

12. Gruppo Italiano Per lo Studio della streptochinesi nell Infarto Miocardio (GISSI).Effectiveness of intravenous thrombolytic treatment in acute myocardial infarction. Lancet 1986;2:397-401.

13. Long term effects of intravenous antistreplase in acute myocardial infarction:final report on AIMS study. AIMS Trial Study Group. Lancet 1990;335(8687):427-31.

14. Acute Myocardial Infarction: Prehospital and in hospital management. The Task Force on the Management of Acute Myocardial Infarction of the European Society of Cardiology. Eur Heart J 1996;17(1):43-63.

15. GUSTO Investigators. An international randomized trial comparing four thrombolytic strategies for acute myocardial infarction. N Eng J Med. 1993;329(10):673-82.

16. Weaver WD. for the National Registry of Myocardial Infarction Investigators (NRMI).Factors influencing the time to hospital administration of thrombolytic theraphy: results from a large national registry (abstract). Circulation. 1992;86(suppl II):2-16.

17. Zhang QT, Hu DY, Yang JG, Zhang SY, ZhangXQ, Liu SS. Public knowledge of heart attack symptoms in Beijing residents. Chin Med J (Engl). 2007 Sep 20;120(18):1587-91.
18. Zerwic JJ. Symptoms of acute myocardial infarction.Expectations of a community sample. Heart Lung. 1998;27(2):75-81.

19. Ashton KC. How men and women with heart disease seek care: the delay experience. Prog Cardiovasc Nurs. 1999;14(2):53-60, 74

20. Goff Jr DC, Sellers DE, McGovern PG, Meischke H, Goldberg RJ, Bittner $\mathrm{V}$, et al. Knowledge of heart attack symptoms in a population survey in the United States: The REACT Trial. Rapid Early Action for Coronary Treatment. Arch Intern Med. 1998;158(21):2329-38.

21. Raczynski JM, Finnegan JR, Zapka JG, Meischke H, Meshack A, Stone EJ, et al.REACT theory-based intervention to reduce treatment-seeling delay for acute myocardial infarction. Am J Prev Med. 1999;16(4):325-34.

22. Conn SV, Taylor SG, Abele PB. Myocardial infarction survivors:age and gender differences in physical health, psychosocial state and regimen adherence. J Adv Nurs. 1991;16(9):1026-1034.

23. Meischke H, To MH, Eisenberg MS, Schaeffer SM, Larsen MP. Reasons patients with chest pain delay or do not call 911. Ann Emerg Med. 1995;25(2):193-7.

24. Gaspoz JM, Unger PF, Urban P, Chvrolet JC, Rutishauser W, Lovis C, et al.Impact of a public campaign on prehospital delay in patients reporting chest pain. Heart. 1996;76(2):150-5.

25. Alonzo AA, Reynolds MR. Responding to symptoms and signs of acute myocardial infarction.How do you educate the public?. Asocialpsychologic approach to intervention. Heart Lung. 1997;26(4):263-72. 